\title{
Feral Horse Distribution, Habitat use and Population Dynamics in Theodore Roosevelt National Park
}

\author{
Clayton B. Marlow — Leonard C. Gagnon — Elena Hovland \\ ANimal and Range ScIENCE DEPartment
}

LYNN R. IRBY

Biology Department ^ Montana State University

BOZEMAN

\section{$\downarrow$ ObJectives}

Description of the ecological niche feral horses fill in Theodore Roosevelt National Park requires information on reproductive rates, home range size, individual and band affinity to home ranges, food and shelter requirements and seasonal diets. Therefore, the initial objectives will be to:

1. identify the number, size and location of home ranges for harem and bachelor stallion bands;

2. describe daily and seasonal movements of bands within identified home ranges;

3. describe the vegetation habitat types and landform types used by horses for mating, foaling, foraging, and resting cover;

4. describe seasonal horse diets; and

5. collect data on sex, age and social hierarchy within respective bands to facilitate estimation of horse population growth rates.
Ultimately, this information will be used to accomplish the project goal; integrate horse requirements with those of elk, bison and the Park's vegetation communities to determine the large ungulate carrying capacity of Theodore Roosevelt National Park.

\section{$\downarrow$ MethodS}

The 1989 and early 1990 field work provided the basis for horse/band identification. We continue recording feral horse use of the various land form types within Theodore Roosevelt National Park.

Field observations and data collection continued as in 1989, e.g. recording horse activity, land form utilized, and population size. Data collection was to have begun in mid-March 1990 but we requested and received an amendment to our research schedule to give our field assistant, Ms. Hovland, the opportunity to take several research design and analysis courses. 
Consequently, field work resumed again on June 1, 1990. Data collection continued until July 13,1990 when Ms. Hovland had to leave the field for personal reasons. We obtained a new field assistant, trained her and resumed observations on August 10, 1990.

\section{$\downarrow \quad$ ResUlts}

On 4 June 1990 there were 90 adult and sub-adult feral horses in Theodore Roosevelt National Park. This was an increase of 18 individuals over the last census on 31 August 1989. (Table 1). Two new bands appeared to have formed over the fall, winter and early spring period bringing the total number of feral horse bands to 10 on 4 June 1990. At the same time, there were 20 foals (1990 births) occurring within nine of the bands for an average of 2.2 foals per band (range of 1-6 per band). However, comparison of total horse numbers between August 1989 and August 1990 does not suggest as large an increase in feral horse numbers as does the August 1989 to June 1990 counts. The inconsistency in horse numbers may result from an animal distribution pattern that makes all horses converge on the Boicourt Springs - Limbo Flats area during late May and June and are easily observed. As the summer progresses, some bands or subgroups of larger bands disperse into the rugged drainages of upper Paddock Creek. such bands and groups could be overlooked in the monthly observations. The absence of the Painted Canyon Son and Little Roan bands from the monthly records after early June (Table 1) supports this argument.

Foal mortality appears to be highest during the first 4-6 weeks of life. Three foals died within the first week; 2 at birth and 1 within the first five days. The cause of death could not be determined. From June to September 1991, two more foals were lost (1 to bison goring and 1 to unknown causes). Four adults shifted from the Brookman and Target bands to the Bad Black, Iron Grey and Boys Club bands. A conservative estimate of horse numbers suggests a population growth rate of less than 1 percent. However, the low mortality among adult horses indicates that the population increase could be significant in terms of the impact on the vegetation community. The likelihood of a negative impact on plant community and soil conditions is further elevated under the present distribution pattern of the feral bands.
Table 1. Size of feral horse bands in Theodore Roosevelt National Park during field observations in 1989 and 1990.

\begin{tabular}{lccc}
\hline \hline & $\begin{array}{c}\text { August } \\
1989\end{array}$ & $\begin{array}{c}\text { June } \\
1990\end{array}$ & $\begin{array}{c}\text { August } \\
1990\end{array}$ \\
\hline Band & 17 & 15 & 14 \\
Brookman & 10 & 10 & 10 \\
Painted Canyon & 12 & 17 & 14 \\
Target & 6 & 5 & 5 \\
Blue Roan/Arab & 9 & 8 & 8 \\
Red Roan & 3 & 7 & 7 \\
Iron Grey & 6 & 10 & 11 \\
Bad Black & 7 & 13 & 9 \\
Boys Club & 1 & 2 & a \\
Painted Canyon Son & 1 & $\underline{2}$ & $\underline{\text { a }}$ \\
Little Roan & 1 & 90 & 78 \\
Total Number of Horses & 72 & & \\
aThese small bands were not relocated after June 1990.
\end{tabular}

Horse use was concentrated in the extreme southeast and eastern portions of the park (Figure 1). This pattern was the same as we had observed in 1989 (Marlow et. al. 1989). The only notable exception was the use of the upland grasslands and rolling scoria landforms between Painted Canyon and Peck Hill during August 1990. However, only the Boys Club, Target and Painted Canyon bands used this area. All other bands continued to concentrate in the BoicourtLimbo Flats-Sheep Butte Springs Complex, and in the upland grassland/introduced grass types immediately adjacent to the Southeast Corner Spring. 


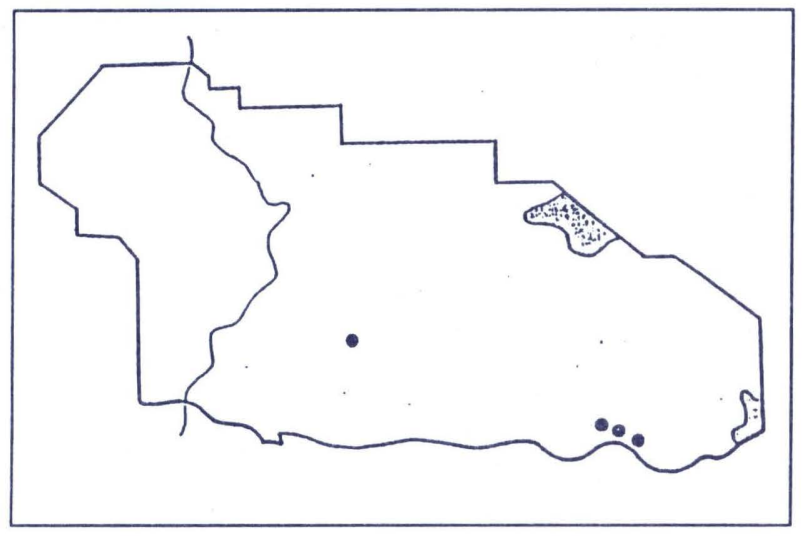

Figure 1. Areas within Theodore Roosevelt National Park that receive continuous use by bands of the feral horses. Stipple pattern represents areas of multi-band concentration. Solid circles indicated where individual bands (Target, Painted Canyon, Boys Club) were found in August 1990.

\section{$\downarrow$ Summary}

The feral horse population within Theodore Roosevelt National Park is growing and the heavy seasonal use of certain areas along the eastern edge of the Park continues. Foal mortality appears to be highest from birth through the first week of life. The number of horse bands in the Park appears to be relatively stable, but winter observation work may help answer the question regarding whether two new bands were actually formed in 1990 . Continual use of a very limited land area by the horses increases the likelihood of overgrazing especially when the concurrent use patterns of elk and bison are included. Long term social stability of individual bands and high fidelity of each band to certain areas suggests that horse management may have to be more intensive, in terms of population manipulation, than for either the elk or bison populations.

\section{$\downarrow$ Literature Cited}

Marlow, C. B., L. C. Gagnon, E. Hovland and L. Irby. 1989. Feral horse distribution, habitat use and population dynamics in Theodore Roosevelt National Park. UW-NPS Res. Cen. Ann. Rep 13: 149-154. 